\title{
The effect of the concept of individual agency on the estimation of health among different age- cohorts
}

\author{
Vylius Leonavicius ${ }^{1, *}$ and Apolonijus Zilys ${ }^{1}$ \\ ${ }^{1}$ Vytautas Magnus university, Department of Sociology, Kaunas, Lithuania
}

\begin{abstract}
The understanding of determinants of health in health policy and health promotion has shifted from a traditional focus on lifestyle (nutrition, exercises, addiction), toward a richer multidimensional approach. This shift has been strongly influenced by a body of research in the human capabilities' approach, which emphasizes the role of person's agency, freedom, and opportunities. Using survey data on 18-52 years old Lithuanian representatives, this paper explores the relationship between personal agency and subjective health perception as well as how it varies depending on the age and post-materialistic values. Human agency refers to the capability of an individual to control personal destiny and make choices to fulfill goals set autonomously (A. Giddens). The results show that agency is important factor of subjective health perception in Lithuania. The fact that capabilities that measure agency are aligned with subjective health measures support the view of human development as an integral process.
\end{abstract}

\section{Introduction}

Contemporary health policy and health promotion programs, human well-being, clean environment and healthy lifestyle are defined as substantial determinants of health. However, multidimensional approach goes further and tries to involve more determinants of personal subjectivity. In the last decades, the understanding of health has shifted from a traditional focus on income and consumption toward a richer multidimensional approach. This shift has been strongly influenced by a body of research in the capabilities' approach, which emphasizes the role of freedom, opportunities, and agency [4, 6-9, 14-15].

The article invites to discuss the relation between subjective health conception among different age-cohorts, and their values attitudes tied to possibilities of agency and age-cohort specific appropriate of modern society type. Two hypotheses: The age cohorts express different levels of the personal and interpersonal agency, and agency is correlated with better assessment of subjective health; the age cohorts express different levels of the postmaterialistic values, and post-materialistic values are correlated with better assessment of subjective health. Hypotheses are based on the notion that different levels of personal agency and post-materialistic values expression between age cohort are the result of different socialization in independent Lithuania and in soviet system.

\footnotetext{
*Corresponding author: vylius.leonavicius@vdu.lt
} 


\section{Theoretical background}

\subsection{Personal agency}

Paper applies pluralistic approach to the analysis of different cohorts and briefly will define the conception of agency (proposed by Anthony Giddens), the theory of human development (proposed by Ronald Inglehart on materialist and post-materialist values). Generalized belief in the role of agency was hypothesized to have a direct positive effect on subjective health conception and to arise from two distinct sources: (a) interpersonal agency (obtaining positive ends through interactions with others) and (b) personal agency (achieving desired outcomes on one's own behalf). The direct antecedent of subjective health is derived from two distinct sources: personal agency or achieving desired outcomes on one's own behalf and interpersonal agency, or obtaining positive ends through interactions with others.

A sudden post-soviet structural transformation of Lithuanian society has induced new conditions of different age cohorts for choosing self-determination and (in)security experiences. These different conditions can be explained by the theories of reflexive, risk or late modernity $[1-3,10,12-13,16-17]$, which are based on the explanation of the interaction between personal agency and structural or institutional determination.

Personal agency refers to the capability of an individual to control his/her destiny and to make choices to fulfill goals set autonomously. Agency refers to the ability to act or perform an action. Agency consequently refers to those things that agents are doing or their capability of doing things. Action or the ability to act by the agency is always interacting with power. A. Giddens's structuralism theory suggests that the agency is the fundamental element to create any sort of change [3]. Change can be thought of as simple as movement through space to interact with a new environment. The "agency-structure" debate in social theory examines the extent to which individuals or collectives are constrained by social-structural contextual forces (such as cultural dynamics, socioeconomic factors, or existing institutional policies and practices), or able to exert influence to change or transform both structural constraints and specific desirable outcomes. During the past period, the different age cohorts lived through the different conditions or socialization and experiences of personal agency. The decision to act, either consciously or not, creates the changes within the agency and the structure that one has influence on the agency.

The conception of the agency could be used as a criterion to identify individuals who belong to the different types of modernity and behave in accordance with it. For example, in the type of second modernity the people are more active, more participate in public area, take more responsibility. It means that different age cohorts that were socialized in the different political and social systems could have different personal agency and might have different subjective assessment.

In addition, the variability of the personal agency could have correlation with different types of values.

\subsection{Human development theory}

The central thesis of the human development theory (developed by Ronald Inglehart and others) is that "economic, cultural and political changes go together in coherent patterns that are changing the world in predictable ways" [12:7]. They proposed that the changes in values are accompanied by the economic development and used the data from World Values Survey (WVS) to prove it. Human development theory makes a distinction between materialistic and post-materialistic values that are defined by two binaries opposition: survival $v s$ self-expression; traditional $v s$ secular-rational values. E.g., the traditional values emphasize 
the following convictions: God is very important in respondent's life; it is more important for a child to learn obedience and religious faith than the independence and determination; abortions are never justifiable; to have a strong sense of national pride or to favour more the respect for authority. The secular-rational values emphasize the opposite convictions. Survival values emphasize different kind of persuasions in life, i.e., individual gives priority to economic and physical security over self-expression and quality-of-life. Survival values are operationalized in WVS, if individual describes himself/herself as not very happy, very careful in trusting other people, less likely to sign petition, has a strong belief that homosexuality is never justifiable. According to the human development theory, the survival values are more common for the individuals of low agency and self-expression values are related to higher level of agency. The individuals with survival values are more statistically likely stress the role of the state in reassuring the public order and stable economy, while and individuals with self-expression values stress the importance of the personal possibilities and freedom. This is an important aspect regarding the analysis of post-soviet or other transitional societies, which have endured significant institutional and structural transformations. An early socialization of different age cohorts usually proceeds during different historical and societal conditions, and, consequently, different type or level of values expressions could be found across generations, which experienced different socialization. In the case of Lithuania (as it is the basis of paper's data analysis), different age cohorts have been brought up in two different systems after the transition from controlled by the state to the market society. Nowadays Lithuanian society could be described as a consumer society with many opportunities to choose compared to the state controlled soviet society, and it stimulates general notion that some age cohorts can assess differently certain aspects in life as more important, their ability to act upon, their personal agency, and even their subjective health.

\section{Methodology}

A theoretical model that links the inter-dependency of subjective health with age cohort and their agency was examined by using the collected data of 3000 respondents. The target population of cross-sectional survey data is $18-52$ years old population living in Lithuania. Data was collected by applying the face-to-face survey mode in 2020 (during the period of inbetween 2 quarantines, July-October months). The net sample of 3000 individuals was collected out of 4634 gross sample (response rate is $65 \%$, which is slightly above the national average). Multistage probability sampling was applied to draw the sample units, which covers Lithuania, and representativeness of sample was guaranteed by using the stratification of national population parameters according to the gender, age (within 18-52 age group), urban-rural and administrative divisions rates.

The data analysis is based on variety statistical methods, but the bivariate analysis is the core of empirical data inspection in this paper. Certain data analysis subsections represent the investigation of differences between two age cohorts: 18-36- and 37-52-years old individuals in Lithuania. Conceptually, two cohorts were distinguished, as these cohorts were socialized under different historical conditions, social experiences, and economic circumstances. Postulating from the theoretical background, age can be a significant factor, which could differentiate individual agency, value orientation and subjective health assessment. It is important in the context of Lithuania, since the individuals of older cohort were born and socialized at the time of soviet period with prevalence of economic limitations (or even shortages) and deficit economy, and the younger Lithuanians have grown up under different societal preconditions of liberal market economy.

However, the age cohort is the only focus in this paper, as we are interested in the interdependency between subjective health and other factors like agency and post-materialist value 
orientation, as well. It should be mentioned that we distinguish between personal agency and interpersonal agency, as the first is associated with individual attitudes and motivations and the second one with expectations directed to other people in society. The further chapters are structured in the following order of conceptual propositions, as we are expecting to find that: higher level of personal agency is correlated with higher levels of subjective health, and higher level of interpersonal agency is correlated with higher levels of subjective health, and post-materialistic value priorities are associated with subjective health. We anticipate that the lower levels of personal and interpersonal agency and more materialistic value priorities should be found among older compared to younger cohort. The variables, which are used to test these propositions, are explained in each subchapter, and certain standardized scales of the survey were adapted from World Values Survey (WVS) [11] and Europeans Social Survey (ESS) [5].

\section{Data analysis}

\subsection{Personal agency and subjective health}

Personal agency concept is measured with three variables -individual personal agency and relative personal agency scales.

Individual personal agency scale is measured at 11-point scale and was rated by the respondent. They answered if they think that they have total freedom to choose and decide how to live a life, or they have little personal choice how to live. The sample distribution scores are leaning towards the right side of scale, i.e., on average, respondents accept a personal responsibility that life's dependency on individual choices $(M=7.39, \mathrm{SD}=2.06)$. However, there are slight significant differences $(t(2792)=6.88,95 \%$ CI [.38-.68], $p<.001)$ between 2 age cohorts (Fig. 1), as the older tends on average to self-assess at the lower end of agency scale $(M=7.65, \mathrm{SD}=1.97)$ compared to younger individuals $(M=7.12, \mathrm{SD}=2.12)$. The age factor has small to medium effect on individual personal agency (Hedge's $g=.26$ ). The relationship between raw age values and agency scores is based on negative weak correlation $\left(\mathrm{r}_{\mathrm{s}}(2846)=-.129, p<.001\right)$, i.e., the decreasing agency level found with increasing age.

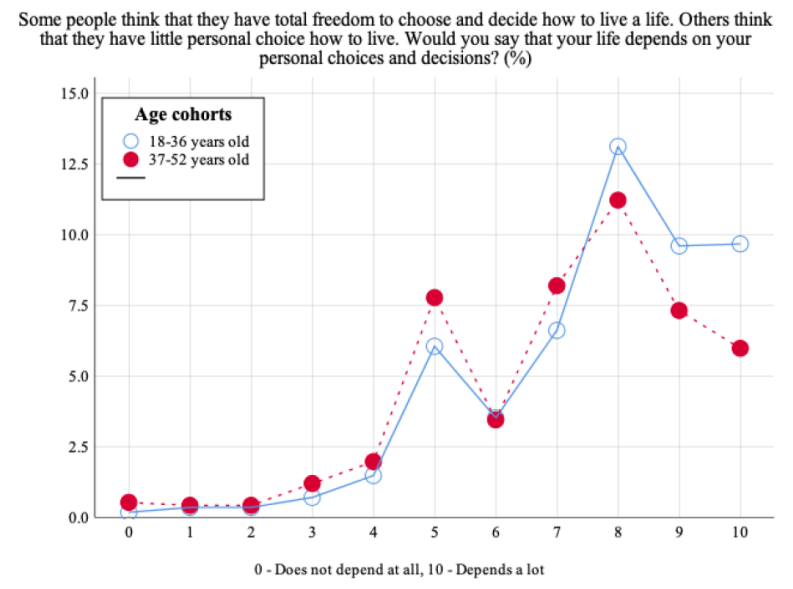

Figure 1. Differences of individual personal agency by age cohorts.

Positive weak correlation was found between the personal agency and subjective health $\left(\mathrm{r}_{\mathrm{s}}(2838)=.181, p<.001\right)$ for the whole sample as well. This suggests that we can find 
slightly higher levels of subjective health with the increasing levels of personal agency. Furthermore, there is even stronger, although still weak, correlation between the personal agency and subjective health among 37-52 years old individuals $\left(\mathrm{r}_{\mathrm{s}}(1463)=.150, p<.001\right)$ compared to younger cohort $\left(\mathrm{r}_{\mathrm{s}}(1375)=.227, p<.001\right)$.

The other two scales of personal agency are composite variables, which were constructed from 7 items. All 7 items were measured on 3-point score scales, whereas respondent had to answer if certain life aspects were (personally) easier, about the same or harder to achieve for him/her compared to the peers (or the same generation). Performed Factor analysis (PCA) $\left(\mathrm{KMO}=.81\right.$ and Bartlett's test $\left.\chi^{2}(28)=12879.34, p<.001\right)$ with Varimax rotation suggested about two factors.

Table 1. PCA factors' loadings for 7 items to validate relative personal agency scales $(N=2592)$.

\begin{tabular}{lcc}
\hline \multicolumn{1}{c}{ Item } & Factor 1 & Factor 2 \\
\hline To find stable job & .63 & \\
To find well-paid job & .65 & \\
To find stable housing & .85 & \\
To find wanted housing & .85 & \\
To take care yourself in future or save for retirement & .62 & \\
To acquire higher than high school education & & .88 \\
To acquire college or university education & & .87 \\
To move somewhere around or outside of Lithuania & & .64 \\
\hline
\end{tabular}

Note: Factor loadings $<.5$ are suppressed.

The first scale of relative personal agency factors with the items belonging to the such life attributes as having stable job, housing, and expecting secure retirement, and the second scale of relative personal agency correlated with the items related to the personal possibilities of better education acquirement and mobility compared to the peers. Table 1 indicates the rotated factor loadings for 2 factors, as the first factor explains $34.82 \%$ and the second one $33.49 \%$ of variance respectively. The items of both factors were added, and two relative personal agency scales (variables) constructed with satisfactory internal consistency (5 items with Cronbach's $\alpha=.86$, and 3 items with Cronbach's $\alpha=.81$ ). Both scales aim to describe individual self-assessment of better or worse opportunities to achieve certain life goals compared to the peers.

Results of bivariate analysis point out that there is significant weak positive relationship between two relative personal agency scales and the subjective health scale, too. It might be added that the relative personal agency based on stable job, housing, and secure retirement assessment slightly more correlates with the subjective health $\left(\mathrm{r}_{\mathrm{s}}(2653)=.197, p<\right.$ $.001)$, though it is still weak relationship, compared to correlation between the relative personal agency based on better education acquirement and mobility and the subjective health $\left(\mathrm{r}_{\mathrm{s}}(2732)=.180, p<.001\right)$. Similar general tendency can be reiterated that the stronger correlation between both relative personal agency and subjective health scales within the subsample of older cohort $\left(\mathrm{r}_{\mathrm{s}}(1288)=.272, p<.001\right.$, and $\mathrm{r}_{\mathrm{s}}(1304)=.224, p<.001$ respectively $)$ than in the subsample of young cohort $\left(\mathrm{r}_{\mathrm{s}}(1365)=.088, p<.001\right.$, and $\mathrm{r}_{\mathrm{s}}(1428)=.097, p<$ .001 respectively). In conclusion, while both relative personal agency scales represent different type of priorities in life, but the higher degree of relative personal agency is associated with the better subjective health assessment, and this tendency is more prevalent among older generation. 


\subsection{Interpersonal agency and subjective health}

This brief subsection is dedicated to show how interpersonal agency is dependent on subjective health among all. We used four variables linked to interpersonal agency (obtaining positive ends through interactions with others), while the variables (Table 2) define the individual expectation and beliefs that the interaction with others is personally beneficial (e.g., discussing personal matters, being more trustful, believe in fairness of others, and helpfulness of others). All 4 variables are adapted scales from ESS study, whereas the first scale offered the ranked number options to choose, and the latter three ones were rated on 11-point scales.

Table 2. Interpersonal agency measurement.

\begin{tabular}{ll}
\hline No & \multicolumn{1}{c}{ Variables of interpersonal agency } \\
\hline 1 & $\begin{array}{l}\text { How many people, if any, are there with whom you discuss intimate and personal } \\
\text { matters? }\end{array}$ \\
2 & $\begin{array}{l}\text { Would you say that most people can be trusted, or that you cannot be too careful } \\
\text { in dealing with people? }\end{array}$ \\
3 & $\begin{array}{l}\text { Do you think that most people would try to take advantage of you if they got the } \\
\text { chance, or would they try to be fair? }\end{array}$ \\
4 & $\begin{array}{l}\text { Would you say that most of the time people try to be helpful, or that they are } \\
\text { mostly looking out for themselves? }\end{array}$ \\
\hline
\end{tabular}

At large, significant weak positive correlation was found between interpersonal agency (all four variables) and subjective health scales. The subjective health is related to the belief or expectation of other's helpfulness $\left(\mathrm{r}_{\mathrm{s}}(2968)=.205, p<.001\right)$, fairness $\left(\mathrm{r}_{\mathrm{s}}(2915)=.173\right.$, $p<.001)$ and trustworthiness $\left(\mathrm{r}_{\mathrm{s}}(2946)=.151, p<.001\right)$, and larger number of people around with whom the personal matters can be discussed $\left(\tau_{\mathrm{b}}(2826)=.110, p<.001\right)$. These variables show the attitudes to the existing conditions of interactions and the presumptions of motivation to ask for the help, i.e., the conditions around people have positive relation to the assessment of subjective health.

The relationship between raw age values and interpersonal agency scores bases on negative correlation, as it was found with personal agency previously. The decreasing scores of expectations in fairness of others $\left(\mathrm{r}_{\mathrm{s}}(2924)=-.076, p<.001\right)$, trustworthiness of others $\left(\mathrm{r}_{\mathrm{s}}(2955)=-.061, p<.001\right)$, and helpfulness of others $\left(\mathrm{r}_{\mathrm{s}}(2977)=-.045, p<.001\right)$ are associated with older age, but it must be mentioned that the correlation is extremely weak.

Interestingly enough, the age variable is interacting at certain level as a peculiar mediating factor between interpersonal agency and subjective health, as well. The same pattern was found after the comparison how strongly interpersonal agency is correlated with subjective health among two different age cohorts, which show different kind of interdependencies. Better health is more associated with helpfulness among older $\left(\mathrm{r}_{\mathrm{s}}(1434)=.216, p<.001\right)$ than younger $\left(\mathrm{r}_{\mathrm{s}}(1523)=.189, p<.001\right)$, more associated with fairness among older $\left(\mathrm{r}_{\mathrm{s}}(1411)=\right.$ $.164, p<.001)$ than younger $\left(\mathrm{r}_{\mathrm{s}}(1501)=.153, p<.001\right)$, and more associated with trustworthiness among older $\left(\mathrm{r}_{\mathrm{s}}(1438)=.187, p<.001\right)$ than younger $\left(\mathrm{r}_{\mathrm{s}}(1512)=.097, p<.001\right)$ individuals. It can be stated that the slightly stronger positive (although still weak) correlation coefficients were consistently found among older than younger generation.

\subsection{Value priority and subjective health}

As it was mentioned, the human development theory proposed the hypothesis that certain economic and other societal changes can bring different type of attitudes and shift the collective values orientations. One of the ways to measure certain attitudes, which might be related 
to agency and health promotion $[6,12]$, is to apply materialist - post-materialist indexes proposed by R. Inglehart and widely used in WVS [11].

Paper applies two indexes (variables) in this chapter, and accordingly they will be called post-materialist scales. Respondents were asked to pick the most important priorities for country to strive for or do in the nearest future from the set of 4 options, and they were asked to choose their first and second priorities according to the importance. Respondents were asked to choose two ranked options for two questions (Table 3), and from each question, the separate scales were constructed. Each question has assigned two materialist and two postmaterialist options, and both post-materialist scales differentiate varies in the following order of scores: 1 - individuals with strong sense of materialistic values, 2 - individuals with mixed type of values, and the score of 3 represents the pure post materialistic sentiment.

Table 3. Inglehart's post-materialist scales.

\begin{tabular}{|c|c|}
\hline $1^{\text {st }}$ post-materialist scale & $2^{\text {nd }}$ post-materialist scale \\
\hline Maintaining order in the nation ${ }^{\mathrm{M}}$ & A high level of economic growth $^{\mathrm{M}}$ \\
\hline Giving people more say in impor- & Making sure this country has strong defense forces ${ }^{\mathrm{M}}$ \\
\hline tant government decision ${ }^{\mathrm{P}}$ & Seeing that people have more say about how things \\
\hline Fighting rising prices ${ }^{\mathrm{M}}$ & are done at their jobs and in their communities ${ }^{\mathrm{P}}$ \\
\hline Protecting freedom of speech $^{P}$ & $\begin{array}{l}\text { Trying to make our cities and countryside more } \\
\text { beautiful }{ }^{\mathrm{P}}\end{array}$ \\
\hline
\end{tabular}

Note: ${ }^{\mathrm{M}}$ represents materialist value orientation, and ${ }^{\mathrm{P}}$ - post-materialist one.

The post-materialist scales are commonly used in the comparative than in cross-sectional studies, as it is quite valid measure to identify how different economic environments and social preconditions are related to different cultural contexts and even lifestyles within materialism-post materialism dimension. As the national data from Lithuania is used in this paper, the age variable can be used and treated as a meaningful factor according to which there might be divergence within materialism-post materialism dimension in a specific country. Different age cohorts were socialized under different economic and social realities, and this might lead to different social preconditions to value personally certain aspects in life over the other. We can expect from the human development theory perspective to find out (on general thesis basis), that younger individuals socialized under more economically secure conditions might tend be more post-materialists compared to older cohort which experienced and lived through the poorer conditions in Lithuania.

Data indicates that the age as a factor is inconsistent with post-materialist values orientation. We found that there is no statistically significant difference in $1^{\text {st }}$ post-materialist scale $(t(2880)=-1.51,95 \%$ CI $[-.07-.01], p>.05)$ between 2 age cohorts, but there is significant difference in comparing the scores of $2^{\text {nd }}$ post-materialist scale between age groups $(t(2883)=5.59,95 \%$ CI $[.08-.16], p<.001)$. Although there are significant differences within $2^{\text {nd }}$ scale scores, but the age factor has extremely small effect on individual attitudes towards post materialistic value orientations (Hedge's $g=.01$ ). Younger tends on average to be more post materialistic $(M=2.08, \mathrm{SD}=.59)$ compared to older Lithuanians $(M=$ $1.95, \mathrm{SD}=.58)$. Performed Kendall's coefficient analysis has not indicated any significant dependency between age cohort and $1^{\text {st }}$ post-materialist scale $($ tb $(2882)=.03, p>.05)$, but there is a weak negative strong association between age and $2^{\text {nd }}$ scale $(\tau \mathrm{b}(2885)=-.10, p<$ $.001)$. So materialistic values are slightly more prevalent among older Lithuanians (19.8\%) compared to younger ones (13.2 proc) (Fig. 2).

While post-materialist scales were inconsistent or indicated just minor anticipated differences across age cohorts, but bivariate statistical analysis showed that both Inglehart's 


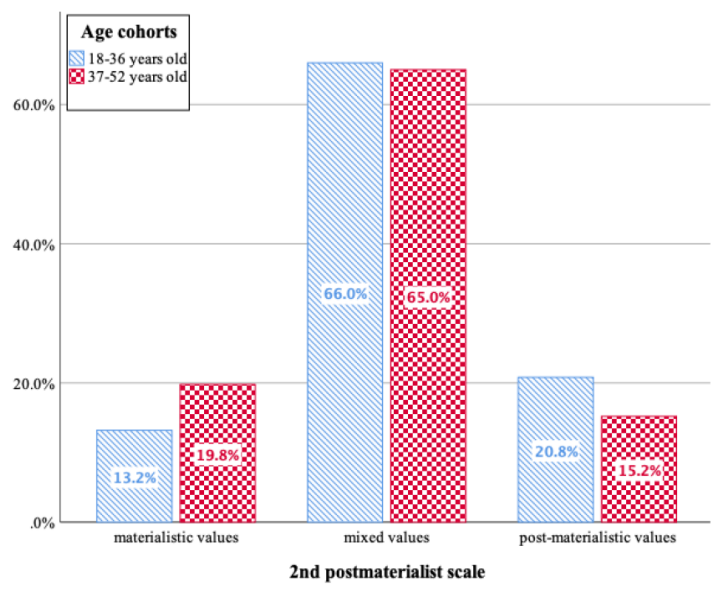

Figure 2. Post-materialistic values (based on $2^{\text {nd }}$ Inglehart's scale) differences by age cohorts.

indexes significantly depend on subjective health assessment. $1^{\text {st }}$ post-materialist index scores slightly higher and negative $\left(\mathrm{r}_{\mathrm{s}}(2873)=-.117, p<.001\right)$ correlation with subjective health scale compared to the $2^{\text {nd }}$ index $\left(\mathrm{r}_{\mathrm{s}}(2885)=.075, p<.001\right)$, which suggest the different type of association. We found inconsistent results with the application of post-materialist measurements. The more individual self-assign worse in subjective health scale - the more post-materialistic priorities increase in $1^{\text {st }}$ measurement, but it is vice versa if we use $2^{\text {nd }}$ measurement of post materialistic values, the more individual self-score better on subjective health - the more post-materialist priorities increase. However, it should be added that the correlations between post-materialist and subjective health scales are quite small.

Similar inconsistencies in post-materialistic values orientation measurements are found if we test for the dependency of personal agency scale. There is weak inverse correlation between personal agency and $1^{\text {st }}$ index $\left(\mathrm{r}_{\mathrm{s}}(2744)=-.069, p<.01\right)$ and positive correlation with $2^{\text {nd }}$ index $\left(\mathrm{r}_{\mathrm{s}}(2749)=.053, p<.001\right)$. It means that the increase in $1^{\text {st }}$ post-materialist scale are related to the decrease of personal agency, but the increase of $2^{\text {nd }}$ post-materialist index is associated with the decrease of personal agency.

Trying to summarize, the post-materialist scales (indexes) are not consistent measurements in trying to look if value priorities are inter-dependent with subjective health or even agency, as it was anticipated. These measures are standardized and used quite frequently in comparative studies [11], hence, we cannot say that post-materialist measurements are not valid methodologically. The inconsistencies of dependency between value priorities and other factors can be partially explained that certain life priorities are predetermined by other factors rather than uni-dimensional attitudes varying from materialist to post-materialist values priority. One of the explanations could be that both cohorts has experienced and were socialized under very similar economic conditions in different times.

\section{Conclusions}

The stages of modern society development could be distinguished by the changes in the material conditions, value priorities, and personal well-being. There is significant research done that individual living in risk society [16-18] or late modernity [1-3] is socialized under more materially and physically secure conditions. As well, the personal agency, which is 
more prevalent and expressed in risk or late modernity society, is more strongly associated with subjective health assessment.

Older Lithuanians have been socialized and lived under authoritative soviet system, which conceptually can be described as an early or first modernity [18]. Following the premises, the paper has postulated the hypothesis that the older Lithuanians scores their subjective health worse compared to younger cohort, as the agency of older Lithuanians is less expressed and they value more material and physical security which is the feature of an early or first modernity. In general, findings show that there are no large differences of attitudes, value priorities, assessment of subjective health and personal agency level between two age cohorts (18-36and 37-52 old Lithuanians). Both cohorts were socialized under different political and economic conditions, but the first decade after the collapse of soviet system was economically insecure and materially unstable period and it might have had a significant implication for the value orientations and early socialization of younger cohort.

However, there is weak correlation among agency, subjective health, value priorities and age cohorts in Lithuania. Older cohort values less their personal and interpersonal (obtaining positive ends through interactions with others) agency, and the lower levels of both agency types are weakly correlated with more poor levels of subjective health. It can be partially concluded that more positive health assessment (found in younger cohort) is not only linked with biological age, but with the higher degree of personal and interpersonal agency.

The younger cohort has experienced the early socialization during the transitional economically insecure and materially unstable period at some point, and, presumably, they manifest significant attitudes of material insecurities [19]. These attitudes linked to material insecurity are very similar to older cohort socialization. This can explain that both cohorts practically do not differ in their assessment of values priority, and value priorities are negligibly, if at all, correlated with subjective health in Lithuania.

This study was supported by the Research Council of Lithuania (Lietuvos mokslo taryba) (Contract No. S-MIP-19-21), and the data presented in the paper was collected as the part of research project: "Experiences of (In)Security across Generations in Lithuania: Motives and Opportunities to Choose Life Trajectories".

\section{References}

[1] A. Giddens, State Society and Modern History. The Nation-State and Violence A Contemporary Critique of Historical Materialism (Palgrave Macmillan, London, 1987)

[2] A. Giddens, The consequences of modernity (Polity, Cambridge, 1990)

[3] A. Giddens, The Constitution of Society (Polity Press, Cambridge, 1984)

[4] D. Hojman, Á. Miranda, Agency, Human Dignity, and Subjective Well-being, World Dev. 101, 1-15 (2018)

[5] European Social Survey, ESS 1-9, European Social Survey Cumulative File, Study Description (NSD, Bergen, 2018)

[6] J. Hunter, M. Franken, D. Balmer, Constructions of patient agency in healthcare settings: Textual and patient perspectives, Discourse, Context Media 7, 37-44 (2015)

[7] J. Page-Reeves, S. Davis, C. Romero, Understanding “Agency" in the Translation of a Health Promotion Program. Prev Sci. 16, 11-20 (2015)

[8] K.L. Frohlich, L. Potvin, Commentary: structure or agency? The importance of both for addressing social inequalities in health, Int J Epidemiol 39, 2 (2010)

[9] N. Wallerstein, Powerlessness, empowerment, and health: Implications for health promotion programs. Am J Health Promot 6, 197-205 (1992) 
[10] R.F. Inglehart, Changing Values among Western Publics from 1970 to 2006, West Eur. Politics 31,130-146 (2008)

[11] R. Inglehart, C. Haerpfer, A. Moreno, C. Welzel, K. Kizilova, J. Diez-Medrano, M. Lagos, P. Norris, E. Ponarin\& B. Puranen et al. World Values Survey: All Rounds - Country- Pooled Datafile (JD Systems Institute \& WVSA Secretariat, Madrid \& Vienna, 2020)

[12] R. Inglehart, H.D. Klingemann, Genes, Culture, Democracy, and Happiness, In E. Diener \& E.M. Suh (eds.), Culture and Subjective Well-Being (MIT Cambridge, 185218, 2000)

[13] R. Inglehart. Modernization and Postmodernization: Cultural, Economic and Political Change in 43 Societies (Princeton University Press, Princeton, 1997)

[14] S. Hitlin, L.D. Erickson, J.S. Brown, Agency and Mental Health: A Transition to Adulthood Paradox, Soc. Ment. Health 5, 3 (2015)

[15] S. Yamaguchi, T. Shiozawa, A. Matsunaga, P. Bernick, U. Sawada, A. Taneda, T. Osumi, C. Fujii, Development and psychometric properties of a new brief scale for subjective personal agency (SPA-5) in people with schizophrenia, Epidemiol. Psychiatr. Sci. 29, e111 (2020)

[16] U. Beck, Risk Society: Toward a New Modernity (Sage, London, 1992)

[17] U. Beck, World Risk Society (Polity Press, Cambridge, 1999)

[18] U. Beck, Ch. Lau, Second Modernity as a research agend: theoretical and empirical explorations in the "meta-change" of modern society. The British Journal of Sociology 56(4), 525-557 (2005)

[19] V. Leonavicius. The Environmental Concern as Criterion of Materialist and Postmaterialist Value Attitudes (Gamtosauginis rupestis kaip matrialistiniu ir pomaterialistiniu vertybiu kriterijus). Humanistika 3, 5 (1999) 